\title{
Crisi social, experiència individual, identitat cultural i acció col+lectiva
}

\author{
Patricia Olivé Conde \\ DAFITS-Universitat Rovira i Virgili \\ patricia.olive@estudiants.urv.cat
}

Resum: Aquest article és un breu resum dels principals aspectes tractats en el projecte de tesi doctoral -en procés de realització- on sanalitzen tant la crisi econòmica i social que s' ha produït en els últims anys com els discursos explicatius que s'han traslladat a l'opinió pública, i també, finalment, com aquests han estat llegits per la ciutadania i com l'experiència dels individus i la lectura que en fan han transformat els seus valors i actituds.

Farem una breu anàlisi bibliogràfica sobre dos dels aspectes claus tractats: en primer lloc, el concepte de Mediterrània com a oposat a Europa i carregat d'un simbolisme associat a estereotips negatius (irresponsabilitat, malbaratament, irracionalitat...), i en segon lloc, les principals transformacions socioeconòmiques anteriors i contemporànies a la crisi financera actual. Ambdós elements, entenem, permeten contextualitzar el procés viscut, alhora que situen els punts de vista dels informants consultats al voltant d'aspectes de la seva identitat i de l'anàlisi de la realitat socioeconòmica; les opinions dels informants constitueixen el nucli de l'article.

Paraules clau: Mediterrània, europeu, crisi, pràctiques quotidianes, discursos

Abstract: This article is a brief summary of the key issues that I have considered in my $\mathrm{PhD}$ thesis (in progress). It analyses the economic and social crisis of recent years, the explanatory discourses that have been offered to the public and, finally, how these discourses have been interpreted by citizens and how these interpretations and their own experiences have changed their values and attitudes.

The article contains a brief bibliographical analysis of two main subjects: first, the concept of 'Mediterranean' - which has a strong symbolic meaning linked to negative stereotypes (irresponsibility, waste, irrationality, etc.) - as opposed to 'Europe'; and second, the main socio-economic transformations 
that occurred prior to and during the current financial crisis. The article argues that these two subjects allow the experience of the crisis to be contextualized and highlight the informants' different points of view about aspects of their identity and the analysis of the socioeconomic reality. The informants' opinions make up the central axis of this research article.

Keywords: Mediterranean, European, Crisis, Common Practices, Discourses

La recerca objecte d'aquest article és la relació que existeix entre els discursos hegemònics que traslladen els mitjans de comunicació massius, el que anomenarem el relat de la crisi, els estereotips culturals que tots compartim, l'aprenentatge que es deriva de l'experiència viscuda i la construcció del propi discurs explicatiu. La construcció d'aquest discurs posa en joc l'assumpció, total o parcial, o el rebuig del discurs oficial, el propi bagatge cultural i la interpretació personal de l'experiència viscuda, $i$ alhora, determina la resposta reactiva davant la realitat social. La construcció del propi relat de la crisi té una íntima relació amb la resposta social dels individus i contribueix a explicar parcialment la configuració de noves realitats socials i polítiques en les nostres societats.

Així, ens proposem fer evidents els relats individuals que expliquen l'evolució de la realitat social en els últims anys, confrontant-los als relats hegemònics, $i$ analitzar-los a partir de dues variables que esdevenen especialment sensibles en aquest context. D'una banda, el contrast d'identitats o no entre el nord i el sud d'Europa i la percepció sobre la construcció europea i les conseqüències que aquesta té per a la vida quotidiana dels individus. En aquest sentit, els referirem a la construcció d'una imatge de la Mediterrània al llarg de la història, especialment a partir del segle xix amb els relats dels viatgers sobre els països del sud d'Europa, i com aquesta és vista per la mateixa antropologia, que a partir de mitjan segle $\mathrm{xx}$ fa d'aquesta àrea una de les seves zones d'estudi privilegiades. D'altra banda, analitzarem com l'experiència de la crisi transforma els comportaments i les visions dels individus i determina la construcció del propi discurs explicatiu sobre la realitat social. Aquesta anàlisi s' ha realitzat a partir d'entrevistes en profundidat als diferents informants. Es tracta de la primera sèrie d'entrevistes que es realitzen en el procés d'elaboració de la tesi doctoral, de la qual el contingut d'aquest article és una primera mostra. 


\section{1. «PIGS in muck»}

El dia 1 de setembre de 2008, quan la crisi econòmica que ens ha trasbalsat en els últims anys tot just śalbirava a l'horitzó i era a penes perceptible com un fet que hagués d'afectar de forma significativa la vida dels europeus, els espanyols i els catalans, el Financial Times publicava un article titulat «PIGS in muck». Larticle feia un joc de paraules entre l'acrònim dels països del sud d'Europa (Portugal, Itàlia, Grècia i Espanya, amb les seves inicials en anglès) i el significat en anglès de la paraula: porcs.

De forma breu, l'article allludia a l'existència d'una prosperitat immerescuda per part d'aquests estats («els porcs poden volar») i la necessària tornada a la realitat («els porcs aterren al femer»). Aquesta prosperitat s'explicaria per l'entrada de capitals estrangers, que, emparats per la unificació monetària a Europa de la mà de l'euro i dels baixos tipus d'interès, haurien finançat els països del sud. L'existència d'elevats dèficits comercials, indicativa del flux de capitals estrangers cap a aquestes economies, justificaria l'alarma davant la crisi econòmica. Una crisi global, tot i que en aquells moments el seu epicentre estava clarament ubicat als EUA com a conseqüència de l'esclat de la bombolla immobiliària, sestén ràpidament als mercats financers globals fins a ofegar la circulació financera. Per als països amb una forta dependència de l'arribada de capitals exteriors, la sequera creditícia esdevé una pèssima notícia.

Llegint l'article no queda dubte que a les consideracions econòmiques més serioses les acompanya un to de menyspreu cap als subjectes analitzats, impropi d'una publicació de la influència i el prestigi del Financial Times, que popularment es coneix com la Bíblia econòmica. ${ }^{1}$ Els països del sud d'Europa, els PIGS, els PORCS, són ràpidament desnonats tot just a l'inici de la crisi, $i$ es vaticina per a ells un futur terriblement negre (convertir-se en cansalada), que lamentablement ha estat el resultat final d'uns anys de terribles i dolorosos sacrificis, especialment per a aquells sectors més desafavorits de la societat. ${ }^{2}$

1 «Países emocionantes consiguen siglas emocionantes, al menos en los círculos financieros. Países con rápido crecimiento como Brasil, Rusia, India y China, por ejemplo, son llamados BRICS, las mismas iniciales implican un crecimiento sólido. Otros países son menos afortunados. Tomemos el caso de Portugal, Italia, Grecia y España, a veces descritos como los cerdos. Es un apodo peyorativo pero tiene mucho de verdad.» Financial Times, 1 de setembre de 2008.

2 Eurostat, al seu informe de 2014, diu que Espanya ha incrementat la seva desigualtat mesurada d'acord amb el coeficient Gini harmonitzat de la renda disponible de les llars equivalents de la UE, des del 0,313 el 2006 a un 0,344 el 2010 i al 0,350 el 2012. D’aquesta manera, Espanya se situa com el segon país més des- 
Una altra mostra de la utilització mediàtica dels antagonismes nacionals han estat les recents polèmiques entre Grècia i Alemanya al voltant de les condicions per a la satisfacció del deute grec i les exigències de la Unió Europea, personificada en Alemanya, a efectes de la visió del poder simbòlic. En aquest sentit, els enfrontaments nacionals, bé siguin a compte d'un suposat mal gest del ministre grec d'economia cap a Alemanya, incloent-hi la polèmica addicional sobre la manipulació audiovisual i l'ètica periodística, o bé a compte dels greuges històrics, com el deute alemany amb Grècia pels danys produïts en l'ocupació durant la Segona Guerra Mundial, han estat llançats a l'opinió pública en paral.lel a les negociacions econòmiques entre els governs. El camp de batalla econòmic, polític i mediàtic se situa clarament en el terreny de les identitats nacionals o, més ben dit, de la confrontació d'identitats nacionals. Unes identitats que beuen fortament dels estereotips, imposats o autoassumits pels mateixos nacionals, i que posen fortament en tensió la identitat europea i clarament el futur de la UE. Abélès posa de manifest com els estereotips nacionals i la divisió nord-sud d'Europa formen part de la cultura de les institucions europees i com aquests estereotips actuen com a elements de confrontació moral.

Put more simply, we often make sense of difference unthinkingly in terms of dichotomy such as rationality/irrationality («we» are rational, «they» are irrational), reason/emotions, realisme/idealism, practicality/impracticality, work/family - and many other similar dualities that can easily and contextualually evoke each other (Abélès, 2004: 17).

\section{La Mediterrània, l'exotització de l'altre proper}

Als anys cinquanta, en el context d'una Europa encara traumatitzada per la Segona Guerra Mundial i de plena efervescència dels moviments anticolonialistes, els antropòlegs britànics, especialment els formats a la Universitat d'Oxford, comencen a veure el sud d'Europa, i en general els països al voltant de la Mediterrània, com un àmbit d'estudi que pot substituir les terres africanes i asiàtiques. La monografia de Pitt-Rivers (1989) sobre els habitants a Grazalema de la Sierra, a la província de Cadis, inicia el que més endavant śanomenarà antropologia de la Mediterrània o, encara més modernament, antropologia de

igual de la UE, darrere de Letònia $(0,357)$ i per davant de Portugal $(0,345)$, Grècia $(0,343)$ i Irlanda $(0,330)$. DE LA DEHESA (2014). 
l'àrea cultural mediterrània. Aquesta àrea d'estudis ha produït nombroses monografies etnogràfiques, així com estudis comparatius amb ànim més generalitzador, i també ha generat nombroses polèmiques entre els que l'han impulsat i els seus crítics, que generalment han estat acadèmics provinents precisament d'aquests països del sud estudiats.

Sens dubte, en els inicis de l'antropologia de la Mediterrània hi influeixen tant elements de caràcter intern de la mateixa disciplina com externs de l'evolució social del món després de la Segona Guerra Mundial (Albera, 1999). Entre els primers, el canvi en el focus d'atenció de l'estudi dels pobles tribals a les societats camperoles, a Àsia, Amèrica Llatina i altres zones. Aquesta transició va començar als anys vint $i$ trenta i es consolida a mitjan segle xx. El focus principal de l'anàlisi de la Mediterrània es produeix quan a Oxford els estudiants d'Evans-Pritchard i Peristiany (per exemple, Pitt-Rivers, Peters, Abou Zeid, Stirling i Campbell) trien com a camp d'estudi les comunitats rurals al voltant de la Mediterrània i es mostren metodològicament més oberts a aproximacions històriques i més crítics amb les del paradigma estructural funcionalista. En un context de lluita per la descolonització, aquestes zones oferien, a més, l'avantatge de la seguretat per al treball etnogràfic.

En la mirada de l'antropologia anglosaxona sobre la Mediterrània, com no pot ser d'altra manera, també hi té un paper molt destacat la configuració que en l'imaginari dels europeus cultes ha tingut la literatura de viatges, que, molt especialment des del segle xviri, ha traslladat a les elits cultes del nord d'Europa una visió «exotizant» dels països del sud. La construcció d'un imaginari cultural en el qual es barregen elements científics, entenent per tal les obres amb pretensió d'objectivitat, literaris i de dominació i control polític, ha estat àmpliament estudiat per Edward Said en el cas de l'Orient (Said, 1990). A la Mediterrània, ens trobem amb un procés potser no tan elaborat ni tan clàssic però en què els relats i les guies de viatges (Borrow i Ford són els més populars) i també les obres literàries (Carmen de Merimée) contribueixen a traslladar una determinada imatge, que posa en relleu les diferències culturals entre els països del nord d'Europa, desenvolupats i cultures, i un sud passional, subdesenvolupat i bàrbar.

No podem aquí estendréns en l'anàlisi d'aquest fenomen, però pensem que val la pena destacar la construcció de l'espai mediterrani com un espai intermedi entre Europa i Àfrica, un espai intermedi entre el nosaltres i l'ells que participa 
parcialment de les dues naturaleses. D'una banda, un passat i un origen civilitzadors (Grècia, Roma) comú als europeus; d'una altra, uns sistemes ecològics i una organització social més semblants als dels països del nord d’Àfrica. No podem obviar que als anys cinquanta, quan els antropòlegs anglosaxons s'apropen a Espanya, a Portugal, a Grècia o a Itàlia (molt especialment la Itàlia del sud), aquests països comparteixen força característiques que els allunyen dels seus veïns del nord. Són països (a excepció d'Itàlia) sumits en dictadures militars, amb una forta presència de la religió, amb sistemes socials tancats, escassament urbanitzats i amb un fort decalatge de desenvolupament econòmic i industrial respecte als països del nord. D'acord amb aquests paràmetres, la Mediterrània es configura com un espai intermedi, ni del tot Europa ni del tot Àfrica, en què els països de la ribera nord i de la ribera sud comparteixen identitat cultural (aquesta no és una visió ni molt menys compartida per tots els antropòlegs que analitzen la regió $i$ ha estat objecte de nombroses polèmiques, especialment pel que fa a l'existència o no de l'àrea cultural mediterrània, que englobaria els països de les dues riberes). Especialment destacades són les polèmiques a Critique of Anthropology durant els anys 1986 i 1987, en què bona part dels antropòlegs més destacats en aquest camp prenen partit, sovint apassionat, sobre el treball de camp desenvolupat a la Mediterrània i, més concretament, sobre la seva utilitat en la posterior construcció teòrica d'una àrea cultural. ${ }^{3}$

L'existència d'aquesta tradició cultural i acadèmica pren relleu en l'anàlisi que ens ocupa a partir del moment que l'explicació que sobre la crisi es dóna des dels mitjans de comunicació de masses obté part de la seva justificació en determinats caràcters nacionals i en els comportaments irresponsables que determinats països han tingut en els anys previs a l'esclat de la bombolla immobiliària. Així, la mateixa existència dels PIGS, identificats com un collectiu homogeni que coincideix a grans trets amb els països preferentment estudiats per l'antropologia de la Mediterrània, i d'un discurs hegemònic que els culpa de la seva situació simbolitzat pel mantra «hem viscut per damunt de les nostres possibilitats», són la prova mateixa de la perversitat nacional o ètnica com a causa de la crisi. ${ }^{4}$

3 L'article inicial de Llobera, J. R. (1986) obre un debat que troba resposta en un seguit d'articles més o menys crítics amb el seu posicionament d’antropòlegs, com Leeds, A., Loizos, P., Pi-Sunyer, C., Pina Cabral, J., Herzfeld, M., Fernández, J. (1987).

4 En aquest sentit, Van Dijk (citat per Howcroft (2012)) ha caracteritzat el discurs intragrup com aquell que els membres dels grups dominants articulen i traslladen mitjançant els mitjans de comunicació massius i les 
La manca de les virtuts associades a l'austeritat, l'estalvi, l'organització i la previsió, pròpies dels pobles racionals del nord i estretament vinculades al protestantisme, esdevé el principal factor que explica el pecat original dels països del sud (la irresponsabilitat) i, per tant, justifica els sacrificis que aquests mateixos països han de fer per expiar aquesta culpa.

Aquests discursos no són, però, unidireccionals, ni provenen sempre d'una posició de domini, sinó que són assumits i repetits pels mateixos destinataris i arriben a constituir la seva pròpia identitat (Herzfeld, 1984).

Un dels objectius de les entrevistes realitzades ha estat l'anàlisi de la interpretació que els individus fem sobre aquesta explicació i sobre quina ha estat la pròpia responsabilitat, tant a un nivell individual com collectiu. ${ }^{5} \mathrm{~S}^{\prime}$ ha demanat també als entrevistats que reflexionin sobre l'existència o no d'aquest àmbit mediterrani i sobre la seva pròpia identitat com a ciutadans europeus en termes de proximitat cultural.

Els testimonis que aquí es presenten són les primeres entrevistes formals enregistrades en el marc del meu treball de camp. Els informants seleccionats corresponen a característiques personals, geogràfiques i biogràfiques diverses. De les sis persones entrevistades, quatre són espanyoles, una és brasilera i un danès. D'aquestes sis persones, cinc es troben entre els 30 i els 45 anys i un té més de 60 anys. No responen a cap mostra ni perfil social determinat, ja que es tracten de les primeres entrevistes realitzades.

La Carlota, ${ }^{6}$ interpel.lada sobre com se sent (catalana, espanyola, europea, mediterrània...), contesta: «No me siento europea ni tampoco solo catalana.

institucions vers els grups subordinats. En aquesta categoria s'inclouen els discursos nord-sud on s'incardinen els comentaris perjudicials dels grups dominants cap als més febles En aquest sentit, Howcroft resumeix el contingut del discurs intragrup hegemònic en la crisi econòmica basat en els estereotips com «lazy, greedy and guilty». És a dir, els països del sud són mandrosos, avariciosos i culpables.

5 Una de les qüestions que interessa analitzar en el treball de recerca desenvolupat és l'encaix entre el discurs hegemònic sobre la crisi, els discursos alternatius i la pròpia experiència de les persones entrevistades, i com aquests elaboren el seu propi discurs sobre les causes i conseqüències de la crisi. En aquest sentit, cal posar de relleu l'aparició, en paral.lel a la del discurs dominant, de discursos alternatius, sorgits no des de les elits i els mitjans de comunicació tradicionals o les institucions, sinó des de l'activisme, internet i les xarxes socials. Aquests discursos alternatius són un fenomen transnacional que a Espanya ha trobat els seus exemples més rellevants en el moviment dels indignats, el 15-M, Democracia Real Ya i, molt especialment, la Plataforma d'Afectats per la Hipoteca. En aquest sentit, resulta especialment rellevant la recepció dels discursos alternatius «desculpabilitzadors» com a eines que faciliten l'alliberament personal i l'empoderament, en paraules de Mangot (2013), extretes dels documents elaborats per la mateixa PAH: «del Prozac a l'empoderament». 6 Trenta-sis anys, llicenciada universitària que exerceix actualment com a professora d'ensenyament secundari i que ha viscut durant cinc anys a Itàlia. 
Quizá española, si me tuviera que identificar, aunque no es la palabra, incluir española o mediterrània.» Tornant a insistir si no se sent europea, ens diuः «No me siento europea ahora; quizás hace más años, cuando era más joven y viví fuera y creía que podía pertenecer a otro país y sentirme ni de aquí ni de allí, pero ahora mismo con el panorama político y social creo que la identidad se ha vuelto más individualista». La Mediterrània només és per a ella un referent cultural: «sí, pero más por cosas culturales».

Aquesta proximitat cultural a la Mediterrània la manifesta també una altra entrevistada, la Carme. ${ }^{7}$ Es tracta, però, també d'una identitat difusa vinculada als referents culturals, musicals i poètics de la Mediterrània: «Uff. Hi ha un munt de cultures diferents. És més poètic.» Kavafis i Maria del Mar Bonet són alguns dels seus referents sobre una construcció basada en l'alta cultura sobre l'existència d'una essència mediterrània.

Aquesta vinculació mediterrània śesgota, però, en la ribera nord. A la pregunta sobre si sestén també a la ribera sud i als països del Magreb, ambdues informants contesten que no.

Altres entrevistats, en canvi, no se senten en absolut vinculats a la Mediterrània $i$, en canvi, sí que se senten més identificats amb el concepte d'Europa. Per exemple, la Marta $^{8}$ considera que no existeix cap tipus d'identitat mediterrània i ni sent cap vinculació cap als països de la ribera sud. Lúnic tret que considera comú als països euromediterranis és «El que podrien tenir en comú és que, en general, són menys pròspers que els del nord i en segons quines polítiques o accions estem menys desenvolupats o anquilosats». La Marta se sent més vinculada a un europeu del nord que a un magrebí o a un sud-americà.

En la mateixa línia van les respostes de la María. ${ }^{9}$ Consultada sobre si té alguna afinitat amb les persones del nord d’Àfrica, ens diuः «¿Hablas de lo que yo siento personalment? Para mí no hay ningún tipo de afinidad.» I preguntada respecte a l'Amèrica del Sud, també ens diu que no. En canvi: «Me siento más afín al Norte; quizás es por mi trabajo o mi relación, en cuestión de sentimientos de cómo me gusta como hacen las coses.» Val a dir que la María ha viscut

\footnotetext{
7 Quaranta-quatre anys, llicenciada universitària que es dedica a l'hostaleria i casada amb una dona brasilera, ara ja amb doble nacionalitat.

8 Quaranta-cinc anys, psicòloga, casada, amb dues filles i una situació econòmica folgada.

9 Quaranta anys, divorciada i amb una filla universitària, treballa com a administrativa en una empresa danesa, ha viscut al Regne Unit i coneix molt bé la cultura danesa d'on és el seu company
} 
al Regne Unit, treballa per a una empresa danesa i la seva parella és danesa, raó per la qual ha viatjat molt sovint a aquest país en els últims anys.

Lexistència o no d'una àrea cultural mediterrània posada damunt la taula de debat per les obres de Davis i Gilmore i pels diversos debats posteriors es basa sobretot en la consideració de determinats trets ecològics (assentament sobre el territori) o sobre la famosa síndrome d'honor/vergonya. Trets objectius que semblen caracteritzar les societats patriarcals i agràries al voltant de la Mediterrània (Davis, 1983 i Gilmore, 1982). La generalització d'aquests trets (patriarcat i masclisme institucionalitzat) entre les societats preindustrials ha portat alguns antropòlegs a preguntar-se si més que característiques mediterrànies no es tracta simplement de característiques preindustrials (Corbin, 1989). La vigència d'algunes d'aquestes característiques en les societats industrialitzades i urbanitzades de l'actualitat sembla força discutible. De les entrevistes realitzades sembla desprendrés la idea que més enllà d'algunes referències culturals, en el sentit de productes culturals (literaris, musicals, etc.) que recullen una suposada essència mediterrània, no existeixen trets diferencials que configurin una identitat mediterrània. Sembla clar que per a les entrevistades la identificació cultural a una àrea mediterrània és molt feble, inexistent si tenim en compte la ribera sud i també molt dèbil i difusa en general. De la mateixa manera, com veurem la identitat europea també és molt feble i en alguns casos inexistent.

D'alguna forma, i tenint en compte el caràcter del tot temptatiu de la hipòtesi, sembla que les categories mediterrani i europeu siguin en certa forma excloents. Tant la Carlota com la Carme, que se senten més vinculades a un concepte cultural de la Mediterrània, entesa com la ribera nord de la Mediterrània, rebutgen totalment una identitat europea. Europa no actua per a elles com un marc de referència. En canvi, per la Marta i la María, que manifesten una nul+la identificació amb el concepte mediterrani, Europa actua com a marc de referència, tot i que es tracta en tots els casos d'una identificació molt feble i amb una escassa càrrega emocional.

En el cas de la Unió Europea i la seva construcció política com un ens supranacional, un estat d'estats, aquesta anàlisi ens portaria a qüestionar-nos si és possible la construcció d'un ens polític amb una absència d'identitat comuna o, fins i tot, amb identitats internes clarament confrontades, com veiem que succeeix en el cas de l'enfrontament grecoalemany, traslladat del terreny de la política econòmica al de l'ofensa i el greuge nacional. 


\section{La fi del pacte capital-treball i la gestació de la crisi econòmica}

Diversos autors han identificat l'actual crisi com el resultat final del trencament del pacte entre el capital i el treball que va caracteritzar l'evolució socioeconòmica dels països occidentals des de la fi de la Segona Guerra Mundial (Krugman, 2009). Així, a partir de mitjans dels anys quaranta del segle passat, la combinació de l'experiència traumàtica de la guerra, la necessitat de suavitzar els conflictes interns per tal d'afrontar la reconstrucció i l'amenaça del model soviètic com a alternativa al sistema capitalista van afavorir que en els països occidentals es donés un progrés significatiu dels drets dels treballadors i les classes populars en el sistema que s'ha conegut com a estat del benestar. El reconeixement dels drets dels treballadors i la força de les organitzacions sindicals van suposar un notable increment en les rendes del treball que va permetre, al seu torn, transformar en consumidors actius els productors (Mateos i Sanz, 2013). Un increment del consum que va afavorir el mateix desenvolupament del capitalisme popular. Al mateix temps, el transvasament de rendes promogut per sistemes impositius eficients i progressius va permetre incrementar notablement la despesa social i proveir de forma universal serveis bàsics com la sanitat i l'educació. Aquest pacte capital-treball, que suposa l'aplicació de polítiques econòmiques de caire keynesià, es trenca però a mitjans dels anys setanta per una nova onada conservadora i liberalitzadora de l'economia que té en els economistes de l'Escola de Chicago els màxims teòrics i en el tàndem Ronald Reagan i Margaret Thatcher els màxims exponents polítics. Larribada al poder a una i altra banda de l'Atlàntic d'aquests dos líders polítics conservadors va suposar la fi del consens sobre el model social. La revolució conservadora volia imposar una visió del món on la lliure competència i el mercat esdevenen la raó última i justificadora de l'organització social. En aquest procés, la destrucció de la força dels sindicats és un dels elements claus. L'altre gran element a combatre són els impostos. Els impostos són vistos com una extracció il.legítima de renda per part de l'Estat que manlleva als ciutadans recursos per malbaratar-los. La caracterització dels impostos com a negativa porta necessàriament a una reducció del paper de l'estat, atès que sense el transvasament d'ingressos provinent del sistema fiscal es queda sense recursos per fer front al sosteniment de les 
polítiques públiques. Així, aviat apareixen els dèficits públics i, a continuació, la necessitat de reduir despeses per equilibrar els pressupostos (Stiglitz, 2010).

El cas espanyol, i en general el dels països del sud d'Europa, segueix ritmes diferents. A mitjans dels anys setanta Espanya, Portugal i Grècia tot just surten de llargues i sanguinàries dictadures i es respira un fort sentiment popular de demanda de justícia social. Es produeix, doncs, una tímida progressió de polítiques públiques tendents a garantir sistemes de protecció social (Seguretat Social), sanitat i educació universals. En definitiva, s'estableixen les bases d'un feble estat del benestar que empara l'evolució econòmica positiva d'aquests estats fins a conduir-los a la integració en les Comunitats Europees (el 1981 per a Grècia i el 1986 per a Portugal i Espanya).

Paral-lelament a aquest procés de revisió del paper de l'Estat als països occidentals, i en part com a conseqüència de la polarització de les rendes que es produeix, té lloc un extraordinari desenvolupament del capitalisme financer. Així, l'increment de la desigualtat i l'acumulació de rendes en els segments més alts de l'escala social porten necessàriament aparellada la necessitat de trobar noves vies d'invertir aquests excedents de capital. L'absència de normes reguladores de l'economia financera, que també forma part del nucli dur de l'ideari conservador neoliberal, el «laissez faire, laissez passer», permet un enorme desenvolupament d'aquest sector. S'incrementa, doncs, d'una banda la necessitat de crèdit, tant per part dels particulars com dels estats. Els primers, les classes treballadores empobrides, els salaris dels quals han perdut poder adquisitiu de forma continuada i ja no tenen el mateix nivell de consum, que només poden assolir mitjançant el crèdit. Els segons, els estats, escanyats també per la manca d'ingressos via impostos, especialment directes, i obligats a mantenir certs nivells de despesa. D'altra banda, s'incrementa també l'oferta de crèdit, atès que l'excés del capital que és necessari invertir ha de trobar alguna sortida. La combinació d'ambdós factors genera bombolles en diferents sectors, emparades per aquest excés de liquiditat que es va movent pels mercats, només limitat per les pròpies espirals inflacionistes produïdes al seu pas. Aquesta història d'excés de capacitat financera és la que explica la bombolla de les puntcom i també la base de l'explicació de l'explosió de la bombolla immobiliària, que és en l'origen de l'actual crisi.

Els mercats financers havien generat la titularització dels actius immobiliaris. És a dir, la generació de drets de crèdit que podien ser intercanviats en els 
mercats financers, a partir de les hipoteques atorgades i garantides amb béns immobles, generalment habitatges. Així, es va organitzar un complex sistema segons el qual el dret de crèdit generat per una hipoteca atorgada a una ciutadà de, per exemple, Detroit, pel préstec rebut per comprar la seva casa, era empaquetat amb altres milers de drets hipotecaris d'arreu dels Estats Units i llançats al mercat com un producte financer que podria ser negociat, comprat $i$ venut $i$ que tenia un preu independent de la seva garantia inicial (el bé immoble, és a dir la casa del ciutadà de Detroit i tota la resta de cases dels ciutadans hipotecats que formaven part d'aquella titularització). Aquests drets estaven garantits per les classificacions sobre el risc que feien les agències de ràting (per exemple Moodys, S\&P) i que servien de guia als inversors a l'hora de definir quins fons (els provinents de fons d'inversió, els de plans de pensions, etc.) s'invertien o no en aquest mercat. A partir del moment que l'escalada del preus immobiliaris, emparada per les polítiques de baix tipus d'interès i la facilitat d'accés al crèdit impulsades per Alan Greenspan des de la Reserva Federal, toca sostre i els preus comencen a caure, la sostenibilitat del sistema de titularització hipotecària sén va en orris com un castell de cartes. A mesura que més hipotecats deixen de pagar i més hipoteques sexecuten, més baixen els preus del mercat immobiliari, s'obté menys de les successives execucions hipotecàries que devaluen el preu dels béns en una espiral que acaba deixant el valor de moltes de les hipoteques titularitzades en pràcticament 0 . El pànic s'estén pels mercats financers i el crèdit es restringeix de forma dràstica. Com en un sistema circulatori ben greixat, el colllapse en un punt del sistema colllapsa ràpidament el conjunt i provoca una paràlisi que ràpidament té conseqüències devastadores.

En el cas europeu, al sistema descrit més amunt per als Estats Units, que són el primer epicentre de la crisi, hem d'afegir els efectes que provoca l'existència d'una moneda única, l'euro, però de sistemes financers independents. Així, malgrat que existeix un mercat europeu únic, el mercat hipotecari està fortament segmentat $\mathrm{i}$ les hipoteques són bàsicament atorgades per les entitats financeres radicades en els països on es troben els immobles. El crèdit interbancari circula però amb fluïdesa, gràcies a l'existència de l'euro i, per tant, els bancs nacionals financen els seus préstecs amb diners provinents d'altres entitats financeres radicades en diferents països. Així, doncs, molts dels excessos del crèdit produïts a l'escalf de les bombolles immobiliàries del sud, com en el cas espanyol, venien finançades pel capital dels bancs alemanys o francesos, que 
actuaven com els prestataris dels bancs espanyols. En una Unió Europea on la banca i els mercats financers tenen una enorme capacitat d'influència política, ${ }^{10}$ l'anàlisi dels seus interessos ens ajuda a entendre els rescats de la banca privada del sud amb capital públic i el segrest de les polítiques públiques dels estats «rescatadors» en mans dels dictats de la troika. La submissió dels mandats democràtics dels governs dels estats als dictats d'aquest grup de tècnics, nomenats per la Unió Europea, el Banc Central Europeu i el Fons Monetari Internacional, esdevé la personificació de les polítiques d'austeritat amb les retallades de la despesa pública i la reducció de drets de les classes treballadores i a l'hora posa seriosament en qüestió els principis de la democràcia i de la sobirania nacional.

Un dels objectius fonamentals de les entrevistes és identificar quin ha estat el propi relat de la crisi que han anat construint els subjectes mitjançant el processament d'informacions diverses, tant provinents dels mitjans de comunicació convencionals com dels seus contactes personals i de la seva pròpia experiència, trajectòria i posicionament ideològic. En aquest sentit, es realitza una pregunta molt directa sobre si poden identificar un o diversos culpables de la crisi.

A la pregunta concreta sobre si podien identificar un culpable de la crisi, la resposta és gairebé unànime. Els polítics en són els responsables, bé per haver pres males decisions, bé per no tenir en compte les necessitats dels ciutadans i només la política financera (Luci) i per la corrupció (Carme). Es detecta una certa «traïció» de la classe política, que ha actuat contra els interessos dels seus electors, per afavorir interessos dels grans grups de poder (la banca i les constructores) o senzillament per obtenir-ne un lucre illlegítim. La Carlota contesta: «La clase política». I la María: «Hombre, a ver: yo lo que creo que los que manejan un país, los que toman las decisiones, son los políticos.» També la Luci, que presenta la idea que els polítics no manen pensant en els interessos de la ciutadania, sinó de les elits: «Bueno, jo penso que la mala administració del govern. La política econòmica, social i financera és molt divergent; no té res a veure una cosa amb una altra, infeliçment». La Marta obre una mica el focus i hi afegeix el sector financer: «Jo crec que són diversos. Com comentava anteriorment, les entitats financeres i els governs dels països han tingut part

10 Navarro, V. (2012) ha caracteritzat el Banc Central Europeu com el lobby de la banca i els mercats financers a l'interior de la UE. Les seves polítiques, suposadament dotades d'independència respecte al mandat polític, atès el seu caràcter tècnic, respondrien segons Navarro als interessos particulars de la banca i no als dels estats ni els seus ciutadans. 
de responsabilitats». Per últim, la Carme posa el dit a la llaga sobre les responsabilitats colllectives. La idea de «viure per damunt de les possibilitats» està present en el seu discurs: «També la corrupció. Se n'aprofiten molt. Hi ha hagut un boom de l'economia i la gent ha gastat molt més del que pot. I després, la corrupció». Les actituds de les persones, el viure per damunt de les possibilitats i fins i tot necessitats (materialisme), formen part també de les causes de la crisi. Les pròpies conviccions, «Jo gasto el que necessito i ja està», contrasten amb el que es considera un excessiu materialisme (aparences, «fardar») davant una actitud personal més espiritual o menys materialista (menys necessitats materials). No es tracta de la mateixa crítica moral implícita a l'afirmació generalitzada de «viure per damunt de les possibilitats» del conjunt del país, entès com un país que no mereix la seva situació de bonança econòmica, sinó com una crisi que posa de manifest un model de societat basat en l'acumulació material que és insostenible. Aquesta crítica esdevé més profunda atès que ataca la mateixa línia de flotació del sistema capitalista, la mercantilització de tots els sectors de la societat i l'extensió del consum a qualsevol preu.

La identificació dels culpables de la crisi està directament relacionada amb la percepció de les causes que l'han provocat. Així, a la pregunta directa sobre quines han estat les causes de la crisi, la majoria d'informants mantenen també la idea que la combinació de la mala administració dels polítics (com a causa principal), el paper de les entitats financeres i, en alguns casos, la irresponsabilitat dels ciutadans que han entrat en una bombolla de consum excessiu a crèdit, han estat les principals causes de la crisi. La Luci, per exemple, ens diu: «Jo també crec que els bancs. La facilitat que tenia la gent d'agafar un crèdit fa quatre, cinc, sis anys enrere per comprar un pis era molt facil, entre cometes; d'això ve la bombolla immobiliària.» I la Carme: «Sí, jo crec que sí que hi ha molta gent que per fardar, i vinga, $i$ anem..., ara podem fer això i crèdits: la gent s'ha entusiasmat.»

Una altra anàlisi es basa en criteris de model econòmic. El model econòmic basat en la construcció i el crèdit era un model insostenible (Marta): «Model econòmic insostenible: les causes han estat una mica que hem viscut en un món basat en uns sectors econòmics poc sostenibles al llarg del temps i que les entitats financeres han tingut una part molt important en el desenvolupament de la situació econòmica que hem viscut i que estem vivint.» 
Un altre element que destaca és la corrupció. Ja hem vist com la Carme la destacava, però no és l'única que en fa esment com una de les causants de la crisi. La María ens diuः «Creo que hay temas que ayudan a que haya más crisis, como la corrupción, que creo que es importante.» O la Carlota: «Uff, pues no sabría decir. Bueno, primero lo que se han embolsado los de arriba»»

Un dels objectius de la recerca és l'anàlisi de la interpretació que els informants fan de les causes i les conseqüències per a ells de la crisi i les polítiques econòmiques dutes a terme, i també l'anàlisi de les afectacions en la seva vida quotidiana i les adaptacions que el context de crisi ha suposat per a ells i elles.

Per tal de conèixer de mà de les mateixes persones protagonistes com ells o elles han registrat la seva experiència, es fa la pregunta "Com t'ha afectat la crisi?», que s'adreça a esbrinar la seva percepció sobre les conseqüències socials, econòmiques, familiars, ideològiques, etc. que els ha produït l'experiència de la crisi en aquests anys. En general, hem observat que els entrevistats tendeixen a minimitzar els efectes de la crisi en la seva pròpia esfera privada. La majoria responen que la crisi no els ha afectat. Per exemple (Carme i Luci):

C: La nostra vida no ha canviat. A veure: sí canvia perquè ara ella per buscar feina... els sous han baixat moltíssim. Si abans es pagava un sou ara sén paga un altre. A hostaleria encara més. Se n'aprofiten molt.

La reacció inicial és dir que la vida no ha canviat, tot i que després, fent referència a realitats concretes, es reconeix el canvi. En el cas d'aquesta parella, una de les dues té moltes dificultats per accedir a una feina i encadena feines de poques hores, mal pagades i d'escassa durada, com més endavant reconeix. La qual cosa suposa un greu perjudici econòmic per als ingressos familiars que les obliga a canviar els seus hàbits de consum. A més, el deteriorament del mercat de treball en l'àmbit de l'hostaleria (que és el seu) també ha tingut una conseqüència clara sobre els seus ingressos.

Una altra visió és la de la María i el Jon, que reconeixen una afectació real i concreta vinculada a la bombolla immobiliària, atès que tenen una casa que no poden vendre a causa de les dificultats en el mercat immobiliari i a la caiguda de preus.

M: A mí no me ha cambiado, mi actitud sigue siendo la misma, pero en cuestiones prácticas sí que me ha afectado; lo que te decía de la casa que ahora no 
se vende. Si la vendes y te quitas la hipoteca tienes más nivel adquisitivo. En un nivel práctico.

En aquest cas però, igual que en l'anterior de la Carme i la Luci, els entrevistats no tenen la sensació d'haver fet cap canvi en la mentalitat o en el seu comportament economicofinancer. A la pregunta sobre si les mesures anticrisi, les anomenades polítiques d'austeritat, l'han afectat d'alguna manera, la resposta de la María és:

A mí en concreto no. Quizás en sanidad, por el tema de que las listas de espera, son mucho más largas... Pero a mí no me ha afectado mucho porque tampoco es algo que utilice demasiado, pero en general creo que sí, lo que te hablaba ahora, el tema de la sanidad, las listas de espera o los recortes que han hecho en hospitales. Esto ha afectado mucho, pero a mi en concreto no me ha afectado mucho el tema, pero en general creo que sí en este sentido de la sanidad... A mí en concreto no.

La María té una filla que estudia a la Universitat; per tant, està plenament afectada per l'enorme augment de les taxes universitàries, així com per la reducció de les beques i l'enduriment per a la seva concessió, però sembla que desconeix aquestes mesures $i$, per tant, no ha identificat aquestes polítiques com un fet que l'afectarà, tot i que tindrà una evident i directa conseqüència sobre la seva situació econòmica. Tampoc les modificacions produïdes en el sistema de pensions durant aquest període o la reforma del sistema laboral i de negociació collectiva són elements que la María identifiqui com que li afectin directament. Per tant, per a ella, en conclusióः «No es más o menos igual porque la empresa está ganando mucho dinero, igual. Ha sido crisis en España, pero en otros países no. En total no ha habido problema.»

Altres entrevistats, tot i que reconeixen els efectes de la crisi sobre la seva situació laboral, no defugen la pròpia responsabilitat personal, a la qual realment culpen de la seva situació. En aquest cas, la Carlota quan es va fer l'entrevista es trobava a l'atur i estava esperant que la cridessin per exercir com a professora substituta en l'ensenyament secundari. Fet que amb posterioritat es va produir. En el moment de l'entrevista portava ja més d'un any sense gairebé ingressos idepenia econòmicament de la seva parella.

C: Me ha afectado personalmente... aunque mi situación personal no la atribuyo solamente a la crisis sino a decisiones personales. Las elecciones de vida 
que he hecho; no me habría afectado tanto si no hubiera vuelto de Italia, donde tenía un trabajo fijo, en el momento en el que vine. Personalmente me afectó porque, claro, en el momento en el que llegué, 2008, que hubo oposiciones, quizás en 2009, no estoy segura, y después ya no se convocaron más, yo perdí aquella oportunidad que era la única oportunidad de hacerlo cuando había y luego que me quedado... así.

En el cas de la Marta, ella reconeix una afectació directa i personal, atès que ha patit un expedient de regulació d'ocupació que la va deixar treballant a temps parcial durant un any al seu lloc de treball. Tot i així, circumscriu els efectes que per a la seva vida ha tingut la crisi a aquest fet, sense anar més enllà sobre les conseqüències de les polítiques publiques aplicades.

En conclusió, doncs, podríem dir que existeix una tendència a minimitzar els efectes de la crisi sobre la pròpia vida. Quan es reconeixen aquests efectes, s'identifiquen exclusivament amb situacions personals (situació d'atur o treball a temps parcial, disminució d'ingressos o dificultats en el mercat immobiliari), i la reflexió sobre els efectes pràctics que sobre la pròpia vida quotidiana tenen les polítiques publiques aplicades durant la crisi es minimitza. Aquest punt entenem que resulta important de destacar, atès que si aquesta identificació no es produeix, és difícil prendre una consciència global de la transformació social que tant la crisi com les polítiques econòmiques emprades, més enllà de la seva discutible eficiència, han tingut per a la vida quotidiana i el futur dels individus. Aquesta visió global és un element indispensable per al posicionament polític, en el sentit més ampli del terme, sobre el futur de la societat.

\section{Conclusions}

El discurs hegemònic intragrup sobre la crisi que sintetitzàvem en l'expressió «Hem viscut per damunt de les nostres possibilitats», socialitzant la culpa de la crisi, sembla que no ha calat entre els informants. Així, malgrat que no es formula un discurs alternatiu articulat, les entrevistades sí que analitzen la crisi com el resultat d'una combinació de corrupció, ineptitud i polítiques esbiaixades en favor de les elits financeres. En una primera aproximació podem concloure que els informants descriuen com la crisi els ha afectat personalment, des de la seva experiència, però no identifiquen els perjudicis per a la seva vida 
quotidiana que les polítiques públiques desenvolupades arran de la crisi, l’anomenat austericidi, han produït.

D’altra banda, malgrat que la crisi ha posat en primer pla Europa com actor polític, la Unió Europea esdevé un marc d’identificació molt llunyà i difús. La crisi financera ha esdevingut a Europa també una crisi política que ha provocat alhora diversos episodis d'inestabilitat política als països del sud d'Europa, l'exemple més significatiu dels quals és Grècia, i una crisi de legitimitat democràtica en la qual les institucions europees han tingut un escàs paper, mentre que ha emergit el poder dur dels estats (especialment d'Alemanya) i d'institucions com el Banc Central Europeu. Les implicacions polítiques de la inexistència d'una identitat europea consolidada són també un dels aspectes en els quals s'haurà d'aprofundir en el futur.

Lescàs nombre d'entrevistes realitzades fa difícil poder parlar de conclusions, atès que són del tot preliminars i temptatives. Més aviat es tracta d'algunes observacions que permetran reorientar el format de les entrevistes. El valor de la informació aportada pels interessats s'incrementa a mesura que reflecteix més les seves pràctiques i no tant els posicionaments generals i abstractes que algunes de les preguntes els plantegen. És en aquest sentit que es replanteja una refocalització del treball de camp, per tal de centrar-lo més en el desenvolupament de les pràctiques quotidianes davant del creixement de la inseguretat econòmica, la pèrdua de drets socials i la precarització laboral en aspectes com les actituds davant el consum i el crèdit i aspectes tan rellevants en l'organització vital com l'accés a l'habitatge. També caldrà analitzar la lectura de la crisi des de l'òptica del plantejament de futur sobre l'acció colllectiva i el posicionament polític, en el sentit més ampli, dels ciutadans. És a dir, triangulant al voltant dels conceptes d'anàlisi de la realitat vivències i pràctiques quotidianes i actituds davant el món de les persones i com l'experiència de la crisi i dels seus discursos les han transformat. 


\section{Bibliografia}

AвÉLÈs, M. (2004) «Identity and Borders: An Anthropological Aproach to EU Institutions», Twenty-First Century Papers (4): 2-26.

Albera, D. (1999) «The Mediterranean as an anthropological laboratoy», Anales de la Fundación Joaquín Costa (16): 215-232.

Borrow, G. (1970) La Biblia en España: o Viajes, aventuras y prisiones de un inglés en su intento de difundir las Escrituras por la Peninsula. Madrid: Alianza. Corbin, J.R. (1989) «The Myth of Primitive Spain», Anthropology Today, 5 (4): $15-17$.

Davis, J. (1983) Antropología de las sociedades mediterráneas. Barcelona: Anagrama.

Fernández, J. (1987) «Field work in Southwestern Europe», Critique of Anthropology, (7): 83-85.

Ford, R. (1988) Manual para viajeros por España y lectores en casa: observaciones generales. Madrid: Turner.

Gilmore, D. (1982) «Anthropology of the Mediterranean Area», Annual Review of Anthropology,(11): 175-205.

Gilmore, D. (1990) «Men and Women in Southern Spain: «Domestic Power» American Anthropologist, New Series (92,4)ः 953-970.

Herzfeld, M. (1980) «Honour and Shame: Problems in the Comparative Analysis of Moral Systems», Man, New Series (15, 2)ः 339-351.

Herzfeld, M. (1984) «The Horns of the Mediterraneanist Dilemma», American Ethnologist, ( 11, 3): 439-454.

Herzfeld, M. (1987) «A view from too far away», Critique of Anthropology, (7): $85-88$.

Howcroft, S. (2012) «The Discourse of the European Finantial Crisis from Different Perspectives» RUA-L (1): 299-319.

KRugman, P. (2009) El retorno de la economía de la depresión y la crisis actual. Barcelona: Crítica.

Leeds, A. (1987) «Fieldwork, history, and the anthropological epistemologyः a critique to Llobera's scientism», Critique of Anthropology, (7): 88-92.

Llobera, J. R. (1986). «Fieldwork in southwestern Europe: anthropological panacea or epistemological straitjacket?», Critique of Anthropology (6):2533. 
Llobera; J.R. (1987) «The Anthropology of Southwestern Europe: the way forward», Critique of Anthropology, (7 ): 101-118.

Loizos, P. (1987) «Reply to Llobera», Critique of Anthropology, (7): 92-96.

Mangot, Ll. (2013) «La Plataforma de Afectados por la Hipoteca. De la crisis a la estafa. Del Prozac al empoderamiento», Clivatge (2):56-87.

Mateos, O. i Sanz, J. (2013) «Cambio de Época ¿Cambio de rumbo? Aportaciones y propuestas desde los movimientos sociales», Cuaderno de Cristianisme i Justícia (186).

Navarro, V. (2012) Los amos del mundo: las armas del terrorismo financiero. Barcelona: Espasa Libros.

Pitt-Rivers, J. (1989) Un pueblo de la Sierra: Grazalema. Madrid: Alianza.

Pi-Sunyer, O.(1987) «Anthropological panacea or epistemological straitjacket», Critique of Antbropology, (7): 96-99.

Pina Cabral, J. (1987) «Anthropology and fieldwork: responses to Llobera», Critique of Anthropology, (7): 83-87.

Pina Cabral, J. (1987) «Replay», Critique of Anthropology, (7): 93-97.

Pina Cabral, J. (1989) «The Mediterranean as a Category of Regional Comparison: A Critical View» Current Antbropology (30,3): 399-406.

SAID, E. (1990) Orientalismo. Madrid: Libertarias-Proudhufi.

Salmon, C. (2008) Storytelling: la màquina de fabricar historias y formatear mentes. Barcelona: Península.

Stiglitz, J. (2010) Caída libre: el libre mercado y el bundimiento de la economia mundial. Madrid: Santillana. 